\title{
Deemed consent for deceased organ donation
}

\author{
Matthew J. Weiss MD, Jade Dirk BSC
}

Cite as: CMAJ 2021 July 5;193:E1008-9. doi: 10.1503/cmaj.210621

I n discussions regarding deceased organ donation policy, few topics generate more debate than deemed consent, often referred to as presumed or opt-out consent. ${ }^{1,2}$ Although variations exist, the basic definition of deemed consent is that all competent members of a jurisdiction are assumed to have given their consent for deceased organ donation unless they have explicitly registered otherwise. Canada joined this international debate on Jan. 18, 2021, when Nova Scotia implemented North America's first deemed consent model. ${ }^{3}$ Policy-makers across Canada are now asking if they should pursue similar policies, but lessons learned from experts around the world suggest that consent models should be changed only with clear objectives in mind and within a transparent system that has other foundational elements already in place. We discuss what is known globally about the impact of deemed consent models, what other jurisdictions have learned about implementation and how the policy should be evaluated in Nova Scotia.

Internationally, deemed consent models have had mixed effects. A 2019 systematic review concluded that countries with deemed consent had donation rates $20 \%-75 \%$ higher than countries using other consent models. ${ }^{4}$ However, only 1 of 6 studies included in the review showed that the consent model was the primary factor influencing donation rates. Instead, national health care expenditures and number of potential donors (closely related to vehicular safety and incidence of strokes) were more closely correlated with donation rates. In contrast, a 2019 analysis of databases from 35 countries did not show a statistically significant donation or transplant advantage to deemed consent. ${ }^{5}$

Even determining the appropriate metric to define success is a topic of debate. Reports often focus on donation or transplant rates, but these measures are influenced by factors independent of the consent model. ${ }^{4,5}$ Consent models do not affect the pool of eligible donors, alter the number of people who need transplantation, or create timely access to operating rooms. Indeed, consent model success would be better measured using metrics such as identification and referral rates of eligible donors, the number of planned approaches that appropriately integrate the possibility of donation into end-of-life conversations and consent rates from approached families. These measures would ensure that systems evaluate how often and how well donation opportunities are integrated into end-of-life care.

\section{KEY POINTS}

- Nova Scotia recently implemented deemed consent for deceased organ donation, and other Canadian provinces are considering a similar change.

- The effects of deemed consent models inernationally have been mixed.

- No matter the consent model, the general public and health care professionals need to operate within a trustworthy and transparent system.

- Analysis of the impact of Nova Scotia's legislative reform is underway and should inform other provinces considering similar changes.

Clear objectives are important, but having a trusted donation and transplantation system before changing a consent model is critical. Organ donation relies on public trust, which must be earned from grieving families at the bedside of a dying or recently deceased loved one. These families must be confident that all appropriate measures to save the life of their loved one were pursued and that organs will be allocated in a just and equitable manner. If a medical system does not have that foundational trust, deemed consent could be seen as an overreach by a system more interested in transplanting organs than treating severely injured patients. ${ }^{6}$ An oft-cited example is that of Brazil in the late 1990s; not even a year after attempted implementation, a deemed consent law was revoked because of widespread distrust of the system and a decrease in donation activity across the country. ${ }^{6}$

Population diversity must also be recognized when implementing a consent model. Concerns within religious or underrepresented communities may be distinct from the broader population, and strategies should be created to address them. Systems and processes should assess and respond to population-specific issues. For instance, as deemed consent has moved from Wales to other regions of the United Kingdom, donation and transplantation officials have created websites that address specific concerns of faith communities based on consultations with leaders and members of those groups. ${ }^{7}$ In these conversations, most expressed concerns were related to organ donation in general, rather than being directly related to deemed consent. However, if trust from a certain group is fragile, deemed consent could give 
the impression of diminishing a person's ability to determine how their body will be treated after death. These concerns should be addressed openly and respectfully before implementing any changes in deceased donation consent models.

The best evidence and experience from other countries suggest that deemed consent is unlikely to be the sole determinant of the performance of a transplant system., ${ }^{8,9}$ However, deemed consent holds a special place of interest among the general public, clinicians and legislators hoping to improve donation performance, and its impact in Canada must be measured. In Nova Scotia, several changes have been incorporated into legislation and will be evaluated over the coming years. Timely audits of potential donors will be used to identify missed referral opportunities and measure meaningful outcomes (e.g., identification and consent rates) that can be compared with other provinces. Specialized training in the methods of approaching families to discuss donation, and recruiting hospital-based donation champions to develop and implement hospital procedures that facilitate donation are additional key interventions that have been associated with improvement; ${ }^{8}$ these will also be incorporated and evaluated. Finally, we have created a multifaceted research program to not only compare quantitative outcomes across provinces, but also to rigorously assess the attitudes of health care workers and the general public regarding these changes. ${ }^{10}$ Special care is being taken to reach out to historically underrepresented groups that may have particular reasons to distrust the concept of presuming consent for donation. No one knows exactly what the impact of the deemed consent policy is going to be in Nova Scotia, but, by studying it carefully, future debates around Canadian consent models will be based less on presumptions and more on data.

\section{References}

1. Gill MB. Presumed consent, autonomy, and organ donation. J Med Philos 2004;29:37-59.

2. Warren M. Opt-out organ donation: Is Nova Scotia's new "deemed consent" law ethical? The Conversation 2021 Jan. 17. Available: https://theconversation.com/ opt-out-organ-donation-is-nova-scotias-new-deemed-consent-law-ethical-152794 (accessed 2021 May 13)

3. Bill 133: an Act respecting human organ and tissue donation. 63rd General Assembly, 2nd session, 2019 Apr. 12. Available: https://nslegislature.ca/legc/ bills/63rd_2nd/3rd_read/b133.htm (accessed 2021 Jan. 13).

4. Ahmad MU, Hanna A, Mohamed A-Z, et al. A systematic review of opt-out versus opt-in consent on deceased organ donation and transplantation (2006-2016). World J Surg 2019;43:3161-71.

5. Arshad A, Anderson B, Sharif A. Comparison of organ donation and transplantation rates between opt-out and opt-in systems. Kidney Int 2019;95:1453-60.

6. Csillag C. Brazil abolishes "presumed consent" in organ donation. Lancet 1998; 352:1367.

7. Organ donations and your beliefs. Bristol (UK): NHS Blood and Transplant. Available: https://www.organdonation.nhs.uk/helping-you-to-decide/your -faith-and-beliefs/ (accessed 2021 Mar. 31).

8. Domínguez-Gil B, Murphy P, Procaccio F. Ten changes that could improve organ donation in the intensive care unit. Intensive Care Med 2016;42:264-7.

9. Hulme W, Allen J, Manara AR, et al. Factors influencing the family consent rate for organ donation in the UK. Anaesthesia 2016;71:1053-63.

10. Weiss MJ, Krmpotic K, Cyr T, et al. A program of research to evaluate the impact of deceased organ donation legislative reform in Nova Scotia: the LEADDR Program. Transplant Direct 2020;7:e641.
Competing interests: Matthew Weiss reports being a paid consultant as medical director for Transplant Québec, a nonprofit provincial organ donation organization. No other competing interests were declared.

This article has been peer reviewed.

Affiliations: Transplant Québec (Weiss), Montréal, Que.; CHU de Québec - Université Laval Research Center (Weiss), Population Health and Optimal Health Practices Research Unit, Trauma-Emergency-Critical Care Medicine, Université Laval, Québec, Que.; Canadian Donation and Transplantation Research Program (Weiss), Edmonton, Alta.; Research \& Innovation (Dirk), Nova Scotia Health Authority, Halifax, NS
Contributors: Both authors contributed to the conception and design of the work, drafted the manuscript, revised it critically for important intellectual content, gave final approval of the version to be published and agreed to be accountable for all aspects of the work.

Funding: This work is funded by a Health Care Policy Contribution Grant from Health Canada through the Organ Donation and Transplantation Collaborative and Nova Scotia Health. The views expressed herein do not necessarily represent the views of Health Canada.

Content licence: This is an Open Access article distributed in accordance with the terms of the Creative Commons Attribution (CC BY-NC-ND 4.0) licence, which permits use, distribution and reproduction in any medium, provided that the original publication is properly cited, the use is noncommercial (i.e., research or educational use), and no modifications or adaptations are made. See: https://creativecommons. org/licenses/by-nc-nd/4.0/

Acknowledgements: The authors thank the panelists, Dr. Beatriz Domínguez-Gil, Dr. Daniela Ferreira Salomão Pontes, Ms. Amanda Lucas, Mr. Phil Walton and Dr. Stephen Beed, who gathered for a roundtable discussion Sept. 14, 2020 at the Transplantation Society's 2020 Virtual Conference. The authors also thank Ms. Cynthia Isenor for her comments.

Correspondence to: Matthew Weiss, matthew.weiss.med@ssss.gouv.qc.ca 